\title{
LA RECONSTRUCCIÓN DE LA MEMORIA CONTRA LA IRREVERSIBILIDAD DEL TIEMPO. REESCRITURAS DEL MELODRAMA EN EL CINE DE JUAN JOSÉ CAMPANELLA
}

\author{
THE RECONSTRUCTION OF MEMORY AGAINST \\ TIME'S IRREVERSIBILITY. REWRITING MELODRAMA \\ IN JUAN JOSÉ CAMPANELLA'S FILMS
}

\begin{abstract}
Nekane E. ZUBIAUR GOROZIKA ${ }^{1}$
Universidad del País Vasco / Euskal Herriko Unibertsitatea

nekaneerritte.zubiaur@ehu.eus
\end{abstract}

Resumen: El artículo analiza la forma en que las películas de Juan José Campanella El mismo amor, la misma lluvia (1999) y El secreto de sus ojos (2009) reformulan algunos de los rasgos principales del melodrama. Ambas películas ponen en escena la reconstrucción de la memoria del personaje, narrada por él mismo, con el objetivo de obtener una segunda oportunidad que le permita recuperar el amor perdido y alcanzar un final feliz. Esta reconstrucción permite además articular un juego reflexivo y metalingüístico en torno a la creación de la ficción y vincular la memoria individual con la memoria histórica y colectiva de Argentina.

Palabras clave: Melodrama. Cine argentino, Juan José Campanella.

\footnotetext{
${ }^{1}$ La autora pertenece al grupo de investigación del Gobierno Vasco "Mutaciones del Audiovisual Contemporáneo (MAC)" con referencia IT 1048-16.
} 
Memoria. Rreflexividad.

Abstract: This article analyzes the way the films by Juan José Campanella Same Love, Same Rain (1999) and The Secret in Their Eyes (2009) reformulate some of the main characteristics of melodrama. Both films show the reconstruction of the main character's memory, told by himself, in order to earn the opportunity of a second chance, the possibility to recover the lost love and come to a happy end. This reconstruction starts a reflexive and metalinguistic game up around the creation of fiction and links individual memory to the historical and collective memory of Argentina.

Key Words: Melodrama. Argentinian cinema. Juan José Campanella. Memory. Reflexivity.

\section{EL DÍPTICO MELODRAMÁTICO DE JUAN JOSÉ CAMPANELLA}

El melodrama latinoamericano ha tenido históricamente en México a su país predilecto y en Arturo Ripstein a uno de sus más inspirados valedores de las últimas cuatro décadas. El director mexicano ha centrado buena parte de sus filmes en las vicisitudes de las clases más humildes de su país puesto que considera que el melodrama no puede evitar plasmar la miseria que habita tanto en los suburbios como en el mundo rural (Ripstein en Pérez Rubio y Hernández Ruiz, 1998: 54). En su opinión, y así lo confirma su filmografía, el celuloide latinoamericano se ha apartado de la tradición hollywoodense del género con "unos melodramas más a flor de piel: personajes que sufren, que tienen que vivir una cotidianeidad descarnada, con sentimientos que afloran a la superficie con más carne y, casi siempre, con brutalidad" (Ripstein en Pérez Rubio y Hernández Ruiz, 1998: 54). 
Con el fin de siglo, sin embargo, surge desde Argentina una nueva voz que se aproxima al melodrama desde un registro diferente al señalado por el veterano cineasta mexicano. Tras debutar en el largometraje con $\mathrm{El}$ niño que gritó puta (The Boy Who Cried Bitch, 1991), el guionista y director Juan José Campanella ha ido alternando periódicas incursiones en el cine con colaboraciones cada vez más asiduas en el medio televisivo, tanto en su país natal como en los Estados Unidos, y su obra ha sido acreedora en los últimos años de una notable repercusión crítica y comercial ${ }^{2}$. Son sus películas El mismo amor, la misma lluvia (1999) y El secreto de sus ojos (2009) las que atañen al objetivo de estas páginas 3 . Con una distancia de diez años entre sí, ambos filmes presentan ciertos vínculos y concomitancias que permiten considerarlos una suerte de díptico melodramático. Por un lado, los dos se centran en sendas historias amorosas, protagonizadas por Ricardo Darín y Soledad Villamil, y enmarcadas — con mayor o menor trascendencia en la trama - por el contexto histórico que envolvió a Argentina entre los años setenta y noventa. Por otra parte, los dos proponen una ambivalente fórmula común en el tratamiento del melodrama, que fundamenta su cañamazo narrativo en la esencia temática del género, al tiempo que altera diversos rasgos distintivos del melodrama canónico.

En las siguientes líneas trataré de evaluar en qué medida ambos títulos pueden suponer una reformulación del modelo melodramático

\footnotetext{
${ }^{2}$ Destacan en la filmografía del director los trabajos cinematográficos: El mismo amor, la misma lluvia (1999), El hijo de la novia (2001), Luna de Avellaneda (2004), El secreto de sus ojos (2009, ganadora del Oscar a la mejor película de habla no inglesa en 2010) y Futbolín (2013), y en televisión la creación de la miniserie hispano-argentina Vientos de agua (100 Bares, Icónica S.A., Pol-Ka Producciones, 2006), así como sus colaboraciones con series norteamericanas como Ley y orden: Unidad de víctimas especiales (Law \& Order: Special Victims Unit, Dick Wolf, NBC, 1999-) o House (House M.D., David Shore, Fox, 2004-2012). Figura asimismo como coguionista y productor ejecutivo de El secreto de una obsesión (Secret in Their Eyes, 2015), remake norteamericano de El secreto de sus ojos, dirigido por Billy Ray.

${ }^{3}$ El mismo amor, la misma lluvia está realizada a partir de un guion original de Campanella junto a Fernando Castets, mientras que El secreto de sus ojos, realizada en coproducción con España, se basa en la novela La pregunta de sus ojos de Eduardo Sacheri, que también interviene en la elaboración del guion.
} 
tradicional, para lo que expondré en primer lugar tanto las principales características que definen universalmente al género, como aquellos rasgos peculiares que han distinguido sus manifestaciones en América Latina. A continuación, apoyada en los fundamentos de la narratología y el análisis fílmico, desgranaré las pautas de la estrategia narrativa que Campanella lleva a cabo en sus películas y el modo en que estas se representan formalmente.

\section{EL MELODRAMA O LA RETÓRICA DEL SUFRIMIENTO}

"En el melodrama se dan cita las más variadas disciplinas de la 'cultura popular' de los últimos siglos: el teatro, la pantomima, la música, la literatura, el cine, la televisión, la fotonovela, el cómic, la canción popular (bolero, tango, fado...) y la radio" (Pérez Rubio, 2004: 35). El cinematógrafo, una de las máximas expresiones de la cultura popular del último siglo, adoptó desde sus orígenes los patrones del género en un buen número de relatos. Hablamos de unos esquemas narrativos y una puesta en escena reconocibles para el público masivo, heredados en cierta medida del originario melodrama teatral del siglo XVIII y XIX, y que a lo largo de los años han definido al género en cualquier latitud: la exagerada acumulación de peripecias providenciales o catastróficas en lugar de circunstancias realistas; un tratamiento que pone el acento en el patetismo y el sentimentalismo de dichas peripecias; la predominancia de una moral maniquea basada en la lucha polarizada entre el bien y el mal que pretende rendir homenaje a la virtud; la notoria presencia de metáforas y signos; y la externalización de las emociones a través de una expresión hiperbólica y una gestualidad exacerbada en busca de la identificación piadosa del espectador (Bourget, 1985; Brooks, 1995).

El protagonista de dicho cúmulo de infortunios y circunstancias desgraciadas responde al arquetipo de la víctima, "encarnación de la inocencia y la virtud, casi siempre mujer” (Martín-Barbero, 1993: 129). Este retrato de la heroína favorece el dispositivo catártico del melodrama que 
"funciona haciendo recaer la desgracia sobre un personaje cuya debilidad reclama todo el tiempo protección -excitando el sentimiento protector en el público- pero cuya virtud es una fuerza que causa admiración y en cierto modo tranquiliza" (Martín-Barbero, 1993: 129).

En el terreno específico del cine, Pablo Pérez Rubio señala que es esa debilidad lo que distingue al protagonista del melodrama de los héroes de la épica y la tragedia, mucho más marcados por la acción: "La principal característica de los personajes del género es la pasividad con que asumen sus heridas, su sufrimiento" (2004: 52). El melodrama se sustenta "sobre el deseo reprimido, no consumado o inalcanzable" (2004: 67-68)" y "solo la aparición de elementos exógenos (un sacrificio ajeno, un golpe favorable del destino...) hará posible, y no siempre, un final relativamente feliz (Pérez Rubio, 2004: 53).

En su destacable estudio, Pérez Rubio ofrece un completo catálogo de rasgos y cualidades distintivos del género, que retoman en buena medida las características procedentes del modelo teatral, y aproximan la identificación emocional y catártica del espectador con el personaje principal a una experiencia de carácter casi masoquista:

Estos filmes recuerdan al espectador la fugacidad de la vida, la presencia constante del dolor físico y emocional, la amenaza permanente de la muerte, la imposibilidad de satisfacer los deseos y de dar soltura a las pasiones individuales más ocultas, las penurias que reportan la inútil búsqueda de la felicidad y la lucha por huir de los designios del destino (Pérez Rubio, 2004: 43).

Sin alejarse de estas pautas generales, el melodrama ha desarrollado en América Latina a través del cine, la radio y la televisión unos moldes particulares que han resultado determinantes para la construcción de los imaginarios colectivos y la identidad nacional. 
En la cultura el populismo se hace nacionalismo y se va a encontrar en el cine -especialmente en el mexicano y el argentino- su mejor medio de expresión y difusión. Si crear un país es en cierto modo teatralizarlo, será el cine el encargado de efectuar esa representación -simbolización mitificadade los gestos y los moldes vitales de lo nacional. Al cine se le encarga darle imagen y voz a las identidades nacionales. $Y$ al cine irán las masas populares no tanto a divertirse cuanto a "experimentar con su vida cotidiana", a "ver reiterados sus códigos de costumbres". Es un cine que [...] hace nacionalismo desde el melodrama: el género capaz de vertebrar cualquier tema o situación a la vez evocando mitos y masificando modos de comportamiento (Martín-Barbero, 1993: 211).

En su análisis sobre la evolución del melodrama mexicano, ejemplo paradigmático del melodrama latinoamericano en su conjunto, Carlos Monsiváis afirma que "en el período que va de fines del siglo XIX a la primera mitad del siglo XX, el melodrama es el fiel escaparate donde se fijan y se 'ennoblecen' los rasgos de la moral tradicional" (1994: 9), es el género que con vocación didáctica "le da a sus espectadores el regalo máximo: la identidad sentimental” (1994: 9):

En materia de captar las exasperaciones anímicas y de negarse a reconocer límites, son insuperables la cinematografía argentina y la mexicana, que hallan sus límites y su desbordamiento en el melodrama, universidad de las rupturas y las reconciliaciones. [...] Sufrir a trasmano y aceptar esa divulgación laica del cristianismo que cada melodrama contiene, es ingresar en el deleite de la expiación sin consecuencias (Monsiváis, 2000: 77 78).

En esa misma línea, Silvia Oroz sostiene que los melodramas latinos, 
convertidos en alegorías nacionales, desempeñaron "una función casi definitiva en la educación sentimental de varias generaciones, entendiendo dicha educación como la construcción de un imaginario y de subjetividades que edificaron un universo simbólico donde amor/sufrimiento/fatalidad son el pasaporte para el paraíso" (Oroz, 1997: 15). El melodrama se convierte en la referencia audiovisual del comportamiento amoroso y para ello se vale de tres elementos: "el desarrollo de una narrativa que asegura la relación cine/público", "la utilización de prototipos y arquetipos que simbolizan las virtudes y maldades, el orden y el desorden patriarcal" y "la planificación y sintaxis común del género melodramático, basadas en una convención lingüística que llega a un público amplio y homogéneo" exportada por Hollywood a escala global (Oroz, 1997: 15-16).

Juan José Campanella conoce bien los resortes de los géneros clásicos americanos, gracias a su formación y extensa experiencia profesional en la industria estadounidense, pero no renuncia a sus raíces latinoamericanas. Es precisamente en su Argentina natal donde ha realizado la mayoría de sus trabajos cinematográficos, aquellos proyectos en los que ha tratado de imprimir un sello más personal superando las limitaciones del medio televisivo. "Varias generaciones latinoamericanas extraen una porción básica de su formación melodramática, sentimental y humorística del equilibrio (precario y sólido a la vez) entre el cine de Hollywood y las cinematografías nacionales" (Monsiváis, 2000: 61). Las estrategias narrativas y fílmicas desplegadas en El mismo amor, la misma lluvia y El secreto de sus ojos dan fe de esa doble vertiente, lo cual no implica, como se analizará a continuación, que el cineasta bonaerense se ajuste con total fidelidad a los patrones inherentes al género en uno y otro ámbito geográfico. 


\section{ANOMALÍAS Y SUBVERSIONES DE DOS PELÍCULAS ESENCIALMENTE MELODRAMÁTICAS}

La primera afirmación que conviene aclarar antes de acometer el análisis narrativo y formal de las películas es precisamente su calificación como melodramas, dado que ambas presentan rasgos suficientes para ser adscritas a otras categorías genéricas. El mismo amor, la misma lluvia se apoya en elementos propios de la comedia combinados con ciertos brotes melodramáticos, en una fusión sintetizada de forma ejemplar en la pequeña escena en la que Jorge (Ricardo Darín) y Laura (Soledad Villamil) deben abandonar una sala de cine, asaltados por el doble acceso de llanto y risas que les produce el viejo drama romántico que están viendo.

La mezcla genérica operada en El secreto de sus ojos reviste, por su parte, mayor complejidad. La película se inicia en 1999 cuando el protagonista Benjamín Espósito (Ricardo Darín), funcionario judicial jubilado, acomete la escritura de una novela que reproduce los acontecimientos que rodearon a la brutal violación y asesinato de la joven maestra Liliana Coloto (Carla Quevedo), ocurrida en 1974. Sucesivos flashbacks muestran a continuación el desarrollo de la investigación del crimen, y el enorme impacto que provoca en el protagonista, en lo que parece ser un thriller policíaco al uso.

Una vez identificado y capturado el asesino, Isidoro Gómez (Javier Godino), el filme deriva sin embargo hacia el drama político, con evidentes alusiones a la corrupción administrativa y al terrorismo de Estado ejercido en los años previos a la dictadura. Gómez es excarcelado para convertirse en escolta de la presidenta María Estela Martínez de Perón e ingresar en las filas de la Triple A (Alianza Anticomunista Argentina) ${ }^{4}$, y desde su nueva posición de poder trata de poner en marcha una venganza contra Benjamín, que acarreará la muerte de su compañero y amigo Pablo

\footnotetext{
${ }^{4}$ Formación parapolicial creada por el sector más conservador del peronismo y auspiciada por el entonces ministro de Bienestar Social José López Rega, con el objetivo de eliminar ilegalmente a quienes se consideraba subversivos.
} 
Sandoval (Guillermo Francella) y le obligará a una precipitada huida de Buenos Aires.

Campanella reconoce abiertamente la influencia que los thrillers norteamericanos de los años setenta han ejercido sobre la película:

Soy un fanático del cine estadounidense de esa década; en mi opinión, la mejor junto a la de los cuarenta. Además, tiene una gran relevancia personal: me crie en esos años, ahí se despertó mi gran amor por el cine. El secreto de sus ojos tiene mucho del thriller politico de los setenta en su interior. Por ejemplo, esos finales que no se cerraban del todo, de gran ambigüedad moral, que dejaban preguntas sin responder (Prieto, 2010).

Por otro lado, tal como delatan los breves apuntes realizados sobre el argumento de la película, el contexto histórico que atañe a la situación política del país entre 1974 y 1976, período en el que se sitúa la acción desarrollada en el pasado, impregna todo el relato dotándolo de una notable carga política. "La película de Campanella no explicita el conflicto de Argentina en esos años ${ }^{5}$ : tangencialmente se percibe el clima de inseguridad y violencia; pese a ser un film de género policial está profundamente contaminado por la realidad social y el contexto histórico argentino de las últimas décadas" (García-Reyes, 2017: 96).

No obstante, y pese a la relevancia de dichas referencias, Campanella es rotundo al declarar cuál es, en su opinión, el auténtico núcleo temático de la obra:

Quizá pueda ser una historia como esta una historia de crimen, sí, pero principalmente de amor. De un amor en estado puro.

${ }^{5}$ García-Reyes (2017: 96) alude en su artículo a unas declaraciones del propio Campanella recogidas en el DVD de la película editado por Cameo Media (2009), en las que señala que "no le corresponde a la película explicar la situación de la Argentina de la época, que por otra parte no mejora el relato, sino que puede distraer la comprensión del mismo, y deja a criterio de cada espectador esa búsqueda de las fuentes". 
De un amor que se terminó cuando era puro capullo, sin darle tiempo a haberse marchitado. [...] La carne, el plato principal, el motor, es el amor callado durante años, la frustración, el vacio que sienten los personajes. El género es el plato en el que esta carne está servida (Campanella, 2009).

Es justamente en la triple historia de amor planteada por la película donde radica su esencia melodramática, en las tramas amorosas conducidas por Benjamín Espósito, Ricardo Morales (Pablo Rago), esposo de Liliana, y el asesino Isidoro Gómez, que articulan el relato de principio a fin.

Esta mezcla de géneros no es algo nuevo; al contrario, durante años se ha convertido casi en norma de la industria cinematográfica con el fin de atraer a la mayor gama de espectadores posible. "Que utilicemos de manera sistemática una sola etiqueta para identificar a una película en concreto no significa que la película se haya adscrito siempre a un solo género, o que no tenga otras características genéricas" (Altman, 2000: 193). El estudioso norteamericano recuerda que, de hecho, esta fórmula de fusión está en el origen de la mayoría de los géneros cinematográficos, que son interfecundables y pueden cruzarse con géneros de todas las épocas. El melodrama en concreto es uno de los esquemas que mejor se ha ajustado a esa cualidad permeable y transhistórica que Altman observa en la evolución de los géneros, por lo que José Javier Marzal ha propuesto la noción de "lo melodramático" frente a la de "género melodrama", entendida como "un sistema de procedimientos textuales en la que podemos identificar una serie de estructuras de reconocimiento: iconográficas, actanciales, espaciales, narrativas y musicales" (Marzal, 1996: 9).

Lo que aquí interesa de la estrategia de hibridación llevada a cabo por el director argentino son las consecuencias que tiene en su particular formulación de las convenciones del melodrama. Ya he señalado la notable presencia de elementos cómicos en El mismo amor, la misma lluvia, pero puede resultar insólito detectar similares tintes humorísticos en El secreto de sus ojos, habida cuenta de los mimbres genéricos que la componen: 
A mi me sale el humor casi sin querer. Trato de escribir una película completamente en serio, pero no hay manera. No concibo una historia, ni siquiera la más dramática, que no incluya elementos de humor. Asi han ocurrido las cosas en mi vida. En ese sentido, la influencia de la comedia italiana en mis películas es bastante acusada (Campanella, 2010).

Este registro cómico, que parece no maridar bien con lo melodramático, aligera en ambos filmes la carga de los demás géneros implicados en el relato ${ }^{6}$ y supone la primera subversión que Campanella ejerce sobre el género. Sus películas se alejan así de la sobrecarga hiperbólica de situaciones desdichadas propia del melodrama universal, pero también de la visceralidad, el sentido de fatalidad y el "tremendismo" que Ripstein, Oroz y Monsiváis (1994: 12), respectivamente, asocian al melodrama latinoamericano:

El cine argentino o el cine mexicano o el brasileño no creen alcanzar un mercado mundial, y confían por tanto en los poderes del exceso; en América Latina el melodrama ha formado a los públicos unciéndolos a su lógica de ir hasta el fondo para allí, en el "cementerio de las pasiones", recobrar la serenidad. [...] Es la potencia del exceso lo que mantiene la lealtad de los latinoamericanos hacia sus melodramas, y la que produce películas extraordinarias (Monsiváis, 2000: 66-67).

\footnotetext{
${ }^{6}$ Como se evidencia en el extenso fragmento narrativo de El secreto de sus ojos en el que Benjamín y su amigo Sandoval se apropian ilegalmente de las cartas que el sospechoso Isidoro Gómez envió a su madre. Una situación típica de thriller policial degenera abiertamente en comedia desde que Sandoval necesita orinar durante la guardia, hasta el instante en que pretende negar la evidencia tras la sarcástica reprimenda del juez, que ha descubierto el chapucero allanamiento de morada perpetrado por ambos sin la pertinente orden judicial.
} 
En realidad, no es del todo cierto que Campanella escape a esa retórica del exceso, puesto que en ambas películas recurre a imágenes y situaciones perfectamente atribuibles al melodrama, que sin embargo el propio autor trata inmediatamente de desmontar. Buena muestra de ello es, por ejemplo, la presentación del personaje de Laura al inicio de $E l$ mismo amor, la misma lluvia. Atrapado en un atasco y entre imágenes borrosas. Jorge descubre un hermoso rostro de mujer sensualmente bañado por la lluvia, que asoma por la ventanilla de un vehículo. Esta romántica visión es en realidad invención del propio Jorge, escritor de relatos, que a lo largo del filme nos hace partícipes de la escritura de su historia de amor con Laura. Un cuento que en su imaginación arranca con dicha imagen. Como comprobaremos más adelante, su primer encuentro real se produce de manera mucho más prosaica: ambos chocan sus narices, literalmente, tratando de huir avergonzados de la proyección de un nefasto cortometraje en el que han participado.

Más tarde, hacia el final del filme, Jorge, hundido personal y profesionalmente, decide suicidarse con ingentes cantidades de alcohol y barbitúricos en una solución eminentemente melodramática, solo empañada por el hecho de que él mismo pone el vídeo de una serie cómica de televisión para acompañar su trágico deceso. Inmediatamente después, vemos a Laura enlutada en el cementerio arrojarse con desconsuelo sobre su féretro. La secuencia, que como la propia voz en off de Jorge reconoce, remeda con evidente sentido paródico el paroxismo del drama a la italiana, vuelve a ser una triquiñuela de la imaginación del protagonistanarrador para engañar al espectador. Unos inestables planos subjetivos nos muestran las verdaderas circunstancias del presunto suicidio, que no hacen sino restar gravedad melodramática al acontecimiento: su amigo Roberto (Eduardo Blanco) lo encuentra en el piso justo a tiempo de obligarle a vomitar.

En El secreto de sus ojos Benjamín también escribe una novela acerca de su fallida historia de amor con su compañera y superior en el 
juzgado, Irene (Soledad Villamil). El adiós de ambos personajes en la estación de tren, cuando Benjamín debe huir de la ciudad amenazado por los secuaces del recién excarcelado Gómez, es uno de los momentos climáticos tanto del relato literario como del fílmico. Benjamín pierde la última ocasión de confesar su amor a Irene y Campanella adorna la puesta en escena con la consecuente parafernalia melodramática: el tren como símbolo de despedida, las manos de ambos tratando de tocarse a través del cristal del vagón, la música melancólica subrayando el dolor de la separación... Cuando Irene lee el pasaje en la novela reprueba el exagerado sentimentalismo de la redacción: "el tipo llorando como si fuera un desgarro, y ella corriendo por el andén como sintiendo que se iba el amor de su vida, y tocándose las manos a través del vidrio como si fueran una sola persona, y ella llorando como si supiera que le esperaba un destino de mediocridad y desamor, casi cayéndose en las vías como queriendo gritar un amor que nunca se había animado a confesar". "Si fue así, ¿o no fue así?”, pregunta Espósito ligeramente sorprendido. "Y si fue así... ¿por qué no me llevaste con vos?”.

No podemos certificar que la situación, tal como se ha escenificado, pertenezca enteramente a la realidad o esté contaminada por cierta recreación ficcional que las emociones de Benjamín hayan podido operar sobre sus recuerdos, que se trate en definitiva del "recuerdo de un recuerdo", tal como lo expresa el personaje de Morales ${ }^{7}$. Pero lo verdaderamente interesante, en lo que atañe al objetivo de estas páginas, es que el triste reproche de Irene pone sobre la mesa el núcleo del conflicto melodramático que atraviesa ambos filmes: el temor del protagonista masculino a enfrentarse a sus sentimientos.

En una nueva transgresión del canon melodramático históricamente dominado por protagonistas femeninas, Campanella concede al hombre el

7Beatriz Sarlo ha señalado que, en efecto, "no hay equivalencia entre el derecho a recordar y la afirmación de una verdad del recuerdo" (2005: 57), ya que todo testimonio se compone "con lo que un sujeto se permite o puede recordar, lo que olvida, lo que calla intencionadamente, lo que modifica, lo que inventa, lo que transfiere de un tono o género a otro", etc. (2005: 79). 
papel central de sus películas. Carolina Rocha (2014) define El secreto de sus ojos como un melodrama masculino conducido por un "hombre caído", un sujeto gobernado por sus emociones, que no posee o que pierde el control, y que fracasa en la búsqueda de su satisfacción personal. En ese sentido, Benjamín Espósito comparte con el Jorge Pellegrini de El mismo amor, la misma lluvia algo más que el rostro y la voz de Ricardo Darín: ambos se enamoran de dos mujeres fuertes y autónomas - encarnadas por Soledad Villamil-y ambos consideran que han malogrado sus trayectorias sentimentales y profesionales. Jorge inicia una relación que parece plena con Laura, pero cuando ella le exige un mayor compromiso, él le responde con una infidelidad que delata su carácter cobarde e infantil. No hace caso de los consejos de la mujer para crecer y madurar como escritor, y le embarga un amargo sentimiento de culpa por la muerte de su amigo periodista Mastronardi (Alfonso De Grazia), al que tampoco se atrevió a ayudar cuando fue relegado al ostracismo por hallarse en la lista negra de la dictadura.

El miedo también paraliza a Benjamín. La diferencia social que lo separa de Irene supone para él un obstáculo insalvable a la hora de confesarle su amor, más aún teniendo en cuenta el compromiso de la mujer con un hombre de su mismo estatus social. En contra de la abierta expresión de las emociones que caracterizaba al melodrama clásico, donde nada queda sin ser dicho (Brooks, 1995: 4), Benjamín está dominado por un silencio temeroso y solo es capaz de hablar a través de sus ojos. A la frustración de no haber consumado su amor por Irene, se suma una doble culpa: por un lado, la certeza de haber defraudado al viudo Ricardo Morales por su impotencia ante la excarcelación e impunidad de Isidoro Gómez. Por otro, como ya le ocurrió a Jorge, su responsabilidad en la muerte de su mejor amigo Sandoval, asesinado por error cuando los hombres de Gómez lo buscaban a él. Estos sentimientos de culpa funcionan como hamartias aristotélicas - errores o fallas cometidos en el pasado por el héroe trágico, cuyas consecuencias debe expiar pese a tratarse a menudo de golpes del destino - y convierten a Jorge y Benjamín en personajes eminentemente 
melodramáticos.

Jorge intenta suicidarse ante el tremendo fracaso de su existencia y Benjamín asegura haber vivido desde su huida de Buenos Aires "una vida vacía", "una vida llena de nada". En esa lacerante sensación de pérdida que atormenta a ambos personajes reside la esencia melodramática de los filmes de Campanella.

Todo, en el melodrama, pivota sobre la pérdida del objeto de deseo amoroso. A nivel narrativo: un trayecto en el tiempo que conduce a la realización de la pérdida anunciada; un sujeto condenado a la pasividad, incapaz de hacer frente a la causa de su sufrimiento, de luchar por la reconquista de su objeto amoroso (González Requena, 1987: 39).

En El secreto de sus ojos dicha pérdida se formaliza narrativa y visualmente en la ya citada despedida en la estación entre Benjamín e Irene, cuyas melodramáticas imágenes sugieren una especie de rima inversa con otra escena de su par El mismo amor, la misma lluvia, acontecida en una comisaría. Pese a las concomitancias señaladas entre una y otra película, ambas historias de amor presentan una notable diferencia: Laura y Jorge consiguen consumar una relación que jamás se concreta entre Benjamín e Irene. Cuando los protagonistas de El mismo amor, la misma lluvia se conocen por primera vez, Laura le confiesa a Jorge que ha leído algunos de sus cuentos y que ha quedado fascinada por "esa cosa de destinos que no llegan a cruzarse”. Ese parece ser el sino de la pareja: encontrarse y separarse como si la confluencia total de sus caminos fuera imposible. Benjamín e Irene por el contrario están obligados a un constante contacto laboral que nunca consigue trascender al terreno de la intimidad. Estas dos dinámicas opuestas tienen su correlato visual en sendos planos en los que las parejas enlazan sus manos.

En la primera cita de Jorge y Laura, la policía irrumpe en el restaurante donde están cenando y ambos terminan arrestados. Separados 
en calabozos contiguos, Jorge le pide a Laura que le dé la mano para comprobar que le han tomado las huellas dactilares, puesto que en los tiempos de la dictadura argentina quien no era fichado tras un arresto corría el riesgo de desaparecer. En el frío vacío de la comisaría, la composición del plano destaca únicamente el contacto físico de ambas manos sin mostrar los rostros de los protagonistas (figura 1), en sentido opuesto a lo que ocurre en el adiós entre Benjamín e Irene, donde ambos se miran con silenciosa impotencia, pero solo pueden unir sus manos de forma virtual a través del cristal del tren que los separa (figura 2).

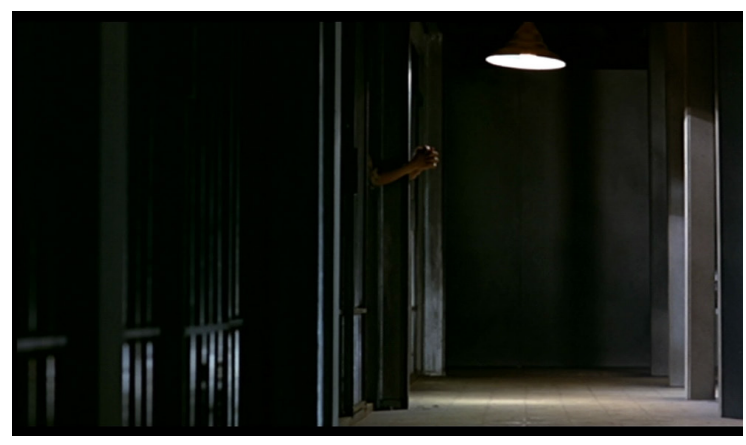

Figura 1

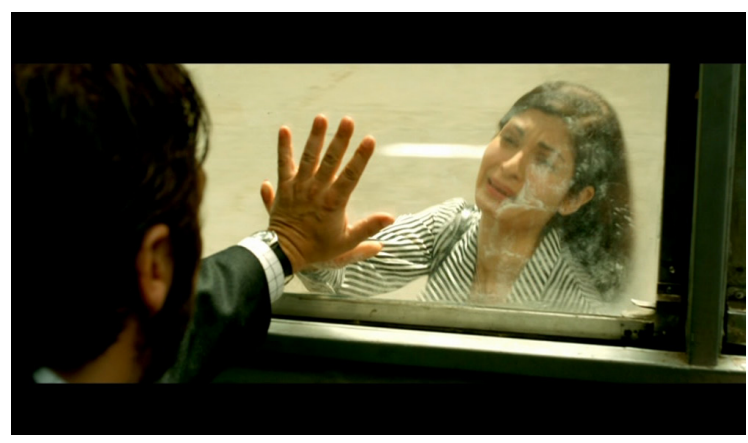

Figura 2

Sea como fuere, ninguna de las dos relaciones podrá fructificar, la comunión total de los amantes será en ambos casos frustrada pese a que sus sentimientos resistan la erosión de los años. Siguiendo las anteriores palabras de González Requena, ambas películas coinciden en plantear sus historias de amor como sendos trayectos en el tiempo: El mismo amor la misma lluvia arranca en 1980 y finaliza en un punto indefinido de los noventa, mientras que El secreto de sus ojos comienza en 1999 y retrocede por medio de sucesivos flashbacks hasta el asesinato de Liliana Coloto, ocurrido en 1974. El tiempo es:

el gran protagonista del melodrama. A diferencia de lo que sucede en el relato de acción, donde el tiempo no es más que el 
ámbito transitivo definido por el encadenamiento de una serie de acontecimientos - de acciones-, en el melodrama todo depende [...] de la puesta en escena del espesor del tiempo irrecuperable (González Requena, 1987: 39).

Francisco Llinásy Javier Maqua(1976:23) señalanla irreversibilidad del tiempo como una de las características fundamentales del melodrama. Ripstein (en Pérez Rubio y Hernández Ruiz, 1998: 56) sostiene además que "el melodrama habla de una imposibilidad para salvarse de los designios del destino". Campanella, sin embargo, parece resistirse a condenar a sus personajes a la implacable acción de ese doble factor de irreversibilidad. El mismo amor, la misma lluvia y El secreto de sus ojos acaban poniendo en escena el esfuerzo de dos personajes inicialmente pasivos por recuperar aquellos objetos amorosos que el tiempo les arrebató. Y ambos lo hacen a través de la memoria y de la escritura.

\section{RECONSTRUIR EL PASADO PARA VIVIR EL PRESENTE}

En el melodrama, "la memoria es el proceso mental que activa el dolor, ese sufrimiento provocado por la imposibilidad de olvidar, y que convierte a muchos personajes en seres anclados en el pasado, en el que se recrean morbosamente, incapaces de vivir en el momento presente" (Pérez Rubio, 2004: 46). En una nueva alteración de los patrones habituales del género, los personajes de Campanella afrontan y reproducen en sus relatos literarios su propio pasado para tratar de enmendar sus errores, cerrar viejas heridas y obtener una segunda oportunidad con la mujer amada. "La memoria vincula pasados con expectativas futuras. Son experiencias pasadas que permanecen, se olvidan y se transforman en su interjuego con circunstancias presentes y expectativas futuras" (Jelin, 2002: 121).

El secreto de sus ojos resume este itinerario de forma brillante por medio del pequeño enigma encerrado en esa nota que Benjamín escribe de manera automática en mitad de la noche. "Temo" es lo que al principio 
del filme parece decir el subconsciente de Benjamín, y lo que queda registrado en el papel. Pero la vieja máquina Olivetti con la que el hombre está redactando su novela - tratando de exponer sobre el papel lo que no pudo expresar oralmente - nos da la clave de la verdadera naturaleza del mensaje. Acostumbrado desde siempre a escribir sin la "A" por un defecto de la máquina, su mente ha omitido inconscientemente esa vocal. Solo cuando decide tomar las riendas de su vida, y un amor ya maduro sustituye al viejo miedo paralizante, puede él mismo completar el acertijo: "TeAmo" (Acosta Larroca, 2009: 64).

En El mismo amor, la misma lluvia Jorge también se vale de la máquina de escribir para alejar sus fantasmas: en primer lugar, confeccionando la obra de teatro sobre su amigo Mastronardi a fin de redimir su sentimiento de culpa, y después, reproduciendo su historia de amor con Laura. La presencia de la máquina a lo largo del filme es constante y significativa. Cuando Laura descubre la infidelidad de Jorge que provoca la ruptura de su relación, el montaje alterna las imágenes de la violenta salida de la mujer de la casa con planos detalle de una página sobre la que las teclas de la Olivetti van imprimiendo una a una y en mayúsculas las letras que conforman una palabra: "Boludo". En ambos filmes la máquina de escribir se convierte en el único canal de comunicación del inconsciente de un protagonista carente de competencia expresiva, el medio que transforma en materia significante los verdaderos sentimientos ocultos en su subconsciente.

Ambas películas recurren también al flashback para plasmar en imágenes la reconstrucción de la memoria. El secreto de sus ojos teje su trama en torno a dos líneas temporales: el presente en el que Benjamín escribe la novela y cierra los cabos sueltos de su vida, y el pasado, que da cuenta de los pormenores de la causa Morales y de los inicios de su amor por Irene. El mismo amor, la misma lluvia, por su parte, presenta una estructura circular que comienza y finaliza con el mismo plano: Jorge se aleja junto a sus amigos bajo la lluvia narrándoles el inicio de su próximo cuento, que no es sino su historia de amor con Laura. Se trata en definitiva 
del cuento que la película irá relatando en un gran flashback, que avanza a través de elipsis temporales marcadas por los sucesivos reencuentros de la pareja — y los acontecimientos históricos que los rodean — a lo largo de casi veinte años.

Nos hallamos, pues, ante sendos personajes-narradores, protagonistas tanto del relato fílmico orquestado por Campanella como del relato literario que ellos mismos articulan en torno a sus recuerdos, unos relatos en los que reconstruyen a través de la ficción toda su vida sentimental. "El discurso de la memoria y las narraciones en primera persona se mueven por el impulso de cerrar los sentidos que se escapan; no solo se articulan contra el olvido, también luchan por un significado que unifique la interpretación" (Sarlo, 2005: 67). En ese afán por comprender y recomponer, sus ficciones no solo relatan su pasado, también lo cuestionan. Paolo Rossi apunta a la inevitable existencia de un "pasado imaginado" en la medida en que este es siempre concebido como algo reconstruido: "La memoria, como se ha dicho 'coloniza' el pasado y lo organiza sobre la base de las concepciones y las emociones del presente" (Rossi, 2003: 87-88). Los recuerdos de los dos protagonistas no parecen del todo fiables. Ya he mencionado los pasajes en los que Jorge dota de cierto halo melodramático a sus peripecias con Laura, para acabar posteriormente ofreciendo la verdadera versión de los hechos. Esta fórmula narrativa demuestra que, solo enfrentándose a la realidad del pasado, al modo en que sucedieron las cosas y no como él las habría imaginado, podrá acometer una relación seria consigo mismo y con Laura en el tiempo presente.

El caso de El secreto de sus ojos es más complejo.

En su obsesión por la búsqueda de la verdad Benjamín se debate entre el recuerdo y la imaginación, entre la memoria y la ficción, aspectos en constante conflicto evidenciados a través de golpes de revés que harán que la historia se reescriba una y otra vez, según el punto de vista cambiante de Benjamín (Acosta Larroca, 2009: 65). 
De los tres principios potenciales que ensaya para la novela - convertidos a su vez en tres inicios para la película—, solo uno pertenece a su memoria, el correspondiente a la despedida con Irene en el andén, que, como se ha dicho, parece, además, fruto de una cierta recreación ficcional. Los otros dos están extraídos de la historia personal de Morales -el último e id́lico desayuno que compartió con su esposa antes de que esta fuera asesinada - y de Gómez — el atroz momento de la violación-, a los que él no pudo asistir ${ }^{8}$. Tal vez en su fuero interno Benjamín considera que esos instantes también son parte de su vida —y así se lo declara a Morales en su última conversación-, dado que forma con esos dos personajes una especie de triángulo especular. El triple arranque del relato es la manifestación de cómo entiende y experimenta cada uno de ellos esa absorbente pasión amorosa a la que no pueden sustraerse por encima incluso del discurrir del tiempo. En la vivencia de esa pasión, Benjamín comparte rasgos de ambos hombres. Él, como Morales, no puede gozar de su objeto amoroso, lo que le provoca un vacío existencial del que es imposible evadirse; pero él también, como Gómez con Liliana, es el otro que no está a la altura de Irene, y cuyos ojos, depositarios de un amor obsesivo, aparecen en todas las fotografías indefectiblemente clavados en ella.

Benjamín quedó desde el principio cautivado por la pureza del inextinguible amor de Morales hacia Liliana, y persigue clausurar la causa porque, al igual que el viudo, él también está atrapado por un pasado que ha embalsamado su vida. Así lo evidencia el hecho de que a lo largo de la película apenas se aprecie ninguna marca enunciativa, más allá del peinado y el maquillaje de los intérpretes, que permita distinguir las dos líneas temporales que entretejen el relato". "Mi presente es lo que me

\footnotetext{
${ }^{8}$ También reproduce, fuera del contexto de la novela que está escribiendo, su hipótesis sobre cómo ocurrió la muerte de Sandoval, suceso que no presenció y que por tanto corresponde una vez más a la ficción-imaginación.

${ }^{9}$ En los comentarios contenidos en la edición en DVD (Cameo Media, 2009), Campanella asegura que planteó un tratamiento cromático diferente en ambas líneas temporales,
} 
compromete, lo que vive para mí, y para decirlo todo, lo que me motiva a la acción, mientras que mi pasado es esencialmente impotente" (Bergson, 2006: 151).

Solo romperá las cadenas de ese pasado impotente cuando se enfrente a sus fantasmas y descubra al fin el modo en que Morales ha podido sobrevivir tantos años a la pérdida de su esposa: manteniendo durante dos décadas a su asesino preso en un cobertizo, sin dirigirle siquiera una palabra. De ese modo cumplirá la condena a perpetuidad que le corresponde por su crimen y, sobre todo, él también, tercer vértice del triángulo, experimentará como ellos lo que es vivir una vida llena de nada. El rostro de Espósito en primer plano observa atónito y consternado el de Morales y el de Gómez, los tres surcados por los barrotes de esa celda, real y figurada, que Morales ha edificado para los tres.

En el pasado habíamos visto a Benjamín pelearse con Romano (Mariano Argento), otro funcionario del tribunal, por quebrantar injustamente la legalidad. En esta ocasión, empero, decide abandonar el lugar sin emitir juicio alguno sobre el descubrimiento ni denunciarlo. La ambigüedad ética del gesto de Benjamín ante la venganza de Morales supone una nueva alteración del melodrama clásico y muy particularmente del latinoamericano, género en el que el triunfo de la moral tradicional es seña de identidad (Monsiváis, 1994; Brooks, 1995: 20; Oroz: 1997). Ese gesto también indica que se ha producido un cambio en el protagonista, capaz al fin de regresar al presente y pasar a la acción con respecto a sus sentimientos amorosos.

La puesta en escena de El secreto de sus ojos está cargada de profusos juegos en torno a la profundidad de foco. El personaje de Benjamín aparece en la mayoría de las composiciones descentrado, situado al fondo del encuadre o rodeado de elementos desenfocados en primer término que obstaculizan la visión del personaje y saturan el plano. Gilles Deleuze

con colores menos saturados en el presente y más vivos en el pasado. La diferencia, no obstante, resulta bastante sutil y una vez inmersos en la película llega incluso a pasar desapercibida. 
conecta el uso de la profundidad de campo con los recuerdos:

la profundidad de campo crea cierto tipo de imagen-tiempo directa que se puede definir por la memoria, por las regiones virtuales del pasado, por los aspectos de cada región. Sería no tanto una función de realidad como una función de memoración, de temporalización: no exactamente un recuerdo, sino "una invitación a recordar" (Deleuze, 2004: 149).

En el momento en que Espósito abandona el cobertizo y sale de cuadro podemos observar al fondo la figura desenfocada de Morales, único elemento iluminado y enmarcado por la puerta. La cámara de Campanella se queda en el umbral para mostrarnos que Morales permanece mientras Benjamín se va, pero renuncia a emplear la profundidad de campo en una última prueba de que el recuerdo del pasado que ha acompañado a Espósito a lo largo de 25 años, esa constante invitación a recordar, se ha disuelto como una sombra.

Cerradas las heridas de la causa Morales, Benjamín se presenta en el despacho de Irene para confesarle al fin lo que ella ya sabe. A lo largo de su relación laboral se ha establecido entre ambos un código en torno a la puerta de esa oficina, una puerta que permanece abierta cuando la cuestión a tratar está relacionada con el trabajo y se cierra cuando es un asunto personal. Fiel a su idiosincrasia, Benjamín solo necesita decir "tengo que hablar con vos", puesto que con solo mirarlo a los ojos Irene comprende de inmediato lo que el hombre pretende anunciar. Ella se adelanta, "va a ser complicado", pero cuando él afirma casi sin aliento "no me importa", Campanella nos ofrece sendos primerísimos planos de los dos personajes con sus rostros ocupando por completo el encuadre, desembarazados al fin de los escorzos, objetos y elementos arquitectónicos que habían obstaculizado hasta entonces la representación y el movimiento de la figura humana. Las últimas palabras de Irene, "cerrá la puerta", son suficientes para clausurar de un portazo el pasado — y el filme - y empezar 
una nueva relación personal lejos de la ficción desplegada ante los ojos del espectador $^{10}$.

El mismo amor, la misma lluvia también finaliza con un rostro y una puerta que se cierra, en un desenlace que nos lleva de vuelta al inicio de la película y del cuento que Jorge redacta a lo largo de la misma. E1 rostro de Laura aparece una vez más bañado por la lluvia a través de la ventanilla de un taxi. Jorge cierra la puerta del vehículo y los dos acuerdan llamarse en lo que parece el germen de una nueva relación que, ahora sí, tiene el principio que Jorge imaginaba y un final aún sin escribir.

Ambos desenlaces aparentemente felices ${ }^{11}$ —última subversión del melodrama propuesta por Campanella - son en realidad finales abiertos, pese a que los protagonistas hayan conseguido hacerse dueños de ese destino que los alejaba de las mujeres amadas y que, retomando las palabras de Ripstein, actúa en el melodrama como una fuerza irremisible.

\section{ENSAYOS METALINGÜÍSTICOS SOBRE LA MEMORIA INDIVIDUAL Y COLECTIVA}

El análisis de El mismo amor, la misma lluvia y El secreto de sus ojos ha puesto de manifiesto la ambivalente estrategia narrativa de Campanella en la construcción de ambas películas. Mantiene por un lado la esencia dramática del melodrama centrando el conflicto de ambas historias en la ausencia o la pérdida de un objeto amoroso aparentemente inalcanzable, y en la configuración de un protagonista arquetípico determinado por su hamartia y su impotencia. Ese núcleo melodramático,

\footnotetext{
${ }^{10}$ Este desenlace conecta con una secuencia anterior en la que Irene cierra la puerta creyendo que Benjamín le va a declarar su amor para evitar que ella contraiga matrimonio con su prometido. Entonces era Sandoval quien impedía que la puerta se cerrara puesto que el verdadero propósito de la conversación era de carácter profesional: solicitar a Irene que reabriera la causa Morales.

${ }^{11}$ En el caso de El secreto de sus ojos el final feliz se refiere únicamente a Benjamín, puesto que, tal como se explicará en las conclusiones, ni Morales ni Gómez conseguirán salir del infierno en que les han sumido sus particulares formas de gestionar su amor por Liliana.
} 
sin embargo, aparece revestido de ciertas formas anómalas que alejan a las dos películas del canon clásico del género: la recurrente presencia del humor, el protagonismo masculino, el rechazo a la retórica del exceso y a la hiperbólica expresión de los sentimientos, el desenlace presuntamente feliz y, sobre todo, la curación de las heridas del tiempo.

Los protagonistas de El mismo amor, la misma lluvia y El secreto de sus ojos han reescrito sus vidas, convertidos en narradores demiúrgicos de su propia existencia, alterando y ficcionalizando en ocasiones algunos de sus pasajes, para invertir el discurrir de un tiempo pasado, dejar atrás miedos y errores, y partir de cero hacia un futuro incierto pero esperanzador donde se les presenta una segunda oportunidad de recuperar el amor de sus vidas.

Las dos películas pueden considerarse en ese sentido metalingüísticas o reflexivas en la medida que plantean un juego narrativo en torno al propio acto de creación. Campanella deja al descubierto ante el espectador los resortes que intervienen en la construcción de la ficción, a través de la acción de sus personajes que funcionan como alter ego del cineasta (Acosta Larroca, 2009: 64). De modo que, mientras Jorge Pellegrini y Benjamín Espósito reescriben y reinterpretan los hechos de su pasado a fin de renovar sus relaciones amorosas, Juan José Campanella también reformula los viejos mecanismos que sustentan al melodrama para dar nueva vida al género y modernizarlo desde su misma esencia.

La operación de Campanella, sin embargo, trasciende el terreno del estudio de los géneros o la narratología, puesto que el afán de sustraerse a la irreversibilidad del tiempo para edificar el futuro no atañe solo a sus protagonistas. No podemos olvidar que "las memorias individuales están siempre enmarcadas socialmente. Estos marcos son portadores de la representación general de la sociedad, de sus necesidades y valores. Incluyen también la visión del mundo, animada por valores, de una sociedad o grupo" (Jelin, 2002: 20). Eso implica, según Jelin, que lo social estará presente en todo ejercicio memorístico, incluso, como es el caso, en los momentos más "individuales". 
Las referencias a la historia reciente de Argentina atraviesan los dos relatos entretejiéndose con sus tramas. En El mismo amor, la misma lluvia la relación de Jorge y Laura, sus esporádicos encuentros y separaciones, coinciden con los sucesos decisivos acaecidos en el país durante la década de los ochenta: las consecuencias de la dictadura, plasmadas en el veto profesional a Mastronardi y la redada a la que son sometidos los protagonistas en su primera cita; la guerra de las Malvinas en 1982; el fin de la dictadura en 1983 y la llegada al poder de Carlos Menem en 1989. Jorge presencia la mayoría de dichos acontecimientos a través del televisor de la redacción del periódico donde trabaja, en el espacio correspondiente a la prensa, responsable oficial de realizar la crónica de la historia y levantar acta de la memoria de la nación. Esa conexión entre los distintos jalones en la relación de los protagonistas y los acontecimientos históricos en los que se enmarcan no solo facilita las elipsis narrativas, sino que evidencia el estancamiento y la impotencia de Jorge con respecto a sus sentimientos hacia Laura: mientras el tiempo avanza sin cesar y Argentina cambia, él continúa inmóvil.

La vinculación de la memoria individual con la memoria histórica resulta en El secreto de sus ojos más evidente, compleja y deliberada:

Me fascina la memoria. Cómo repercuten hoy en día decisiones que hemos tomado hace veinte, treinta años. La memoria que también puede ser la de una nación. Hoy, que estamos recuperando la memoria de los años setenta como país, sabemos que el horror comenzó a gestarse antes de la dictadura militar. La historia transcurre en esa Argentina en que el aire comenzaba a espesarse, envolviendo y sorprendiendo aun a sus propios protagonistas (Campanella, 2009).

Hugo Hortiguera ha destacado que Campanella retrasa con respecto a la novela la fecha del asesinato de Liliana y la excarcelación de Gómez 
para situarlos en el momento en el que el Estado argentino comienza a vulnerar la ley para garantizar su continuidad ${ }^{12}$. Teniendo en cuenta que la película fue realizada durante el mandato de Cristina Fernández de Kirchner, cuando desde el gobierno se estaba impulsando una suerte de idealización y reformulación de ciertos sucesos de los períodos peronistas, Hortiguera considera que la película polemiza con esa representación oficial de la memoria manifestando las negativas consecuencias que la desintegración del Estado de derecho tuvo sobre el país y la sociedad. Al final del filme, "lo nefasto que [Benjamín] descubre es algo que va mucho más allá del castigo ilegal al que ha quedado sujeto Gómez. Es el descubrimiento de una fascinación perversa por lo atroz que atraviesa la sociedad argentina y de la que él no escapa" (Hortiguera, 2010). Benjamín trata de cerrar sus heridas personales, pero en paralelo, el filme "busca atar los cabos sueltos interpretativos de la historia nacional reciente para poder entender y desentrañar su presente" (Hortiguera, 2010).

Ana Moraña también interpreta en clave política la actitud de los personajes masculinos a lo largo del filme. Moraña entiende que Espósito "busca recuperar a través de la palabra, la memoria antes que la misma se extinga; esta, para él, es una forma de hacer justicia, o al menos de salvar del olvido a las víctimas" (2011: 384), mientras que para Morales la recuperación de la memoria no es compensación suficiente para la injusticia cometida.

Ha quedado establecido que el núcleo melodramático del filme se sustentaba en las diferentes interpretaciones del amor que realizan los tres personajes masculinos, y es en la memoria de esos tres hombres donde permanece vivo el recuerdo de la víctima Liliana (García-Reyes, 2017: 102). Al conocer el destino del asesino, Benjamín logra al fin clausurar el capítulo de la causa Morales, pero "el recuerdo silenciado de Gómez [...] es el de un ser humano desarticulado en el que la soledad absoluta y la negación de comunicación por parte del carcelero hacen inexistente

\footnotetext{
${ }^{12}$ En la novela de Sacheri La pregunta de sus ojos, el asesinato de Liliana se produce en 1968.
} 
su posibilidad para el recuerdo" (García-Reyes, 2017: 102). En el caso de Morales:

no se intuye redención alguna: en el sacrificio vital se aprecia la enorme contradicción del marido viudo al que se le niega justicia, la víctima convertida en victimario, sustituyendo al Estado de derecho y a los órganos judiciales, [...] aplicando una suerte de ojo por ojo. De esta forma, recordar a Liliana se convierte para Morales en otra forma de condena (García-Reyes, 2017: 103).

A través de las trayectorias de Benjamín y Morales, Campanella pone sobre la mesa dos posiciones enfrentadas en torno a la función de la memoria en sociedades que han vivido, como Argentina, períodos de brutal represión, abusos y vulneración de los derechos humanos y violencia ejercida con impunidad por el Estado. "Susan Sontag escribió: 'Quizá se le asigna demasiado valor a la memoria y un valor insuficiente al pensamiento'. La frase pide precaución frente a una historia en la que el exceso de memoria [...] puede conducir, nuevamente, a la guerra" (Sarlo, 2005: 26). Esa es precisamente la situación de Morales, tan enfermizamente leal al recuerdo de su esposa que queda enquistado en un irracional anhelo de venganza y justicia personal, tan ilegítima como la que dejó sin castigo el asesinato de Liliana. Benjamín, por el contrario, encarna el movimiento "de conquista de la palabra y de derecho a la palabra", reforzado "por una ideología de la 'sanación' identitaria a través de la memoria social o personal” (Sarlo, 2005: 50). Representa en ese sentido la postura defendida por Beatriz Sarlo, que en el fondo está "movida por la convicción de Sontag: es más importante entender que recordar, aunque para entender sea preciso, también recordar" (Sarlo, 2005: 26).

Para comprender el motivo por el que el cineasta argentino recurre al melodrama a fin de llevar a cabo estas reflexiones, basta retomar las siguientes palabras de Jesús Martín-Barbero: 
Ningún otro género [...] ha logrado cuajar en la región [América Latina] como el melodrama. Como si en él se hallara el modo de expresión más abierto al modo de vivir y sentir de nuestras gentes. [...] Porque como en las plazas de mercado, en el melodrama está todo revuelto, las estructuras sociales con las del sentimiento, mucho de lo que somos — machistas, fatalistas, supersticiosos-y de lo que soñamos ser, el robo de la identidad, la nostalgia y la rabia. En forma de tango o de telenovela, de cine mexicano o de crónica roja el melodrama trabaja en estas tierras una veta profunda de nuestro imaginario colectivo, y no hay acceso a la memoria histórica ni proyección posible del futuro que no pase por el imaginario (1993: 243).

Las múltiples implicaciones y niveles de significados que las dos películas ponen en juego, así como la persistencia de unas mismas inquietudes temáticas y estrategias discursivas en dos textos separados por diez años, señalan a Juan José Campanella como un cineasta coherente, comprometido y consciente de las potencialidades de su labor fílmica. Un cineasta capaz no solo de aunar las raíces culturales de un país (el melodrama latinoamericano como forma de expresión popular de los sentimientos de una colectividad) con su pasado histórico a través de los recursos del cine, sino de proponer nuevas formas narrativas que conecten el discurso sobre la regeneración, personal y colectiva, implícito en los relatos con la regeneración del género en el que estos se encuadran. 


\section{REFERENCIAS BIBLIOGRÁFICAS}

ACOSTA LARROCA, P. (2009). "El secreto de sus ojos: El mismo autor, la misma obra". Revista Atticus 9, 57-68, http://www.revistaatticus. es/old/Revistas/Revista_Atticus_9.pdf [07/02/2018].

ALTMAN, R. (2000). Los géneros cinematográficos. Barcelona: Paidós.

BERGSON, H. (2006). Materia y memoria. Ensayo sobre la relación del cuerpo con el espíritu. Buenos Aires: Cactus.

BOURGET, J.L. (1985). Le mélodrame hollywoodien. París: Stock.

BROOKS, P. (1995). The Melodramatic Imagination. Balzac, Henry James, Melodrama and the Mode of Excess. New Haven y Londres: Yale University Press.

CAMPANELLA, J.J. (2009). "Juan José Campanella escribe sobre El secreto de sus ojos", http://www.abcguionistas.com/ noticias/articulos/11111111111111111111111111111115d8/juanjose-campanella-escribe-sobre-el-secreto-de-sus-ojos.html [17/04/2018].

DELEUZE, G. (2004). La imagen tiempo. Estudios sobre cine 2. Barcelona: Paidós.

GARCÍA-REYES, D. (2017). "De luz y de sombras: los fantasmas de la memoria en El secreto de sus ojos". Archivos de la Filmoteca 73, 91-106 (también en http://www.archivosdelafilmoteca.com/index. php/archivos/article/view/553 [07/01/2018]).

GONZÁLEZ REQUENA, J. (1987). “Escenografía de la herida”. En Acerca del melodrama, V. Ponce (coord.), 38-41. Valencia: Conselleria de Cultura, Educació i Ciència de la Generalitat Valenciana.

HORTIGUERA, H. (2010). "Políticas del recuerdo y memorias de la política en El secreto de sus ojos de Juan José Campanella". Ciberletras. Journal of Literary Criticism and Culture 24, http://www.lehman. cuny.edu/ciberletras/v24/hortiguera.html [07/02/2018].

JELIN, E. (2002). Los trabajos de la memoria. Madrid: Siglo XXI. 
LLINÁS, F. y MAQUA, J. (1976). El cadáver del tiempo. El collage como transmisión narrativa/ideológica. Valencia: Fernando Torres.

MARTÍN-BARBERO. J. (1993). De los medios a las mediaciones. Comunicación, cultura y hegemonía. Barcelona: Gustavo Gili.

MARZAL, J.J. (1996). Melodrama y géneros cinematográficos. Valencia: Episteme.

MONSIVÁIS, C. (1994). "Se sufre, pero se aprende (el melodrama y las reglas de la falta de límites)". Archivos de la Filmoteca 16, 7-19 (también en http://www.archivosdelafilmoteca.com/index.php/ archivos/article/view/340 [20/03/2018]).

(2000). Aires de familia. Cultura y sociedad en América Latina. Barcelona: Anagrama.

MORAÑA, A. (2011). "Memoria e impunidad a través del imaginario cinematográfico: La mujer sin cabeza (Lucrecia Martel, 2008) y El secreto de sus ojos (Juan José Campanella, 2009)". Revista de Crítica Literaria Latinoamericana 73, 377-400.

OROZ, S. (1997). "Porque te amo quiero salvarte: discurso amoroso, sociedad y melodrama cinematográfico en América Latina". Secuencias. Revista de Historia del Cine 6, 15-21.

PÉREZ RUBIO, P. (2004). El cine melodramático. Barcelona: Paidós.

PÉREZ RUBIO, P. y HERNÁNDEZ RUIZ, J. (1998). "Mis melodramas son más desnudos, más esencialistas, que los norteamericanos". En El cine de Arturo Ripstein. La solución del bárbaro, VV.AA., 5257. Valencia: Ediciones de la Mirada.

PRIETO, C. (2010). "Los asesinatos previos a la dictadura se asumían con toda tranquilidad". Diario Público, http://www.publico.es/ culturas/asesinatos-previos-dictadura-asumian-tranquilidad.html [17/04/2018].

ROCHA, C. (2014). "El secreto de sus ojos: An Argentine Male Melodrama". New Cinemas: Journal of Contemporary Film 12 (1\&2), 3-15 (también en http://www.ingentaconnect.com/content/ intellect/nc/2014/00000012/F0020001/art00001? crawler $=$ true 
LA RECONSTRUCCIÓN DE LA MEMORIA CONTRA LA IRREVERSABILIDAD DEL TIEMPO ReEscrituras DEL MELODRAMA EN El CINE DE JuAN José CAMPANella

[20/03/2018]).

ROSSI, P. (2003). El pasado, la memoria, el olvido. Buenos Aires: Nueva Visión.

SARLO, B. (2005). Tiempo pasado. Cultura de la memoria y giro subjetivo. Una discusión. Buenos Aires: Siglo XXI.

Recibido el 8 de febrero de 2018.

Aceptado el 13 de mayo de 2018. 
